\title{
The auricular differences with advancement in age and darwinian tubercle in Igbo and Yoruba ethnic groups in Nigerian
}

\begin{abstract}
Background: This study was done to determine the differences in mean auricular lengths, auricular widths and earlobe lengths of males and females with increase in age, prevalence of pendulous and non-pendulous earlobes and Darwinian tubercle in the Igbo and Yoruba ethnic groups of the adult Nigerian population.
\end{abstract}

Materials and methods: These measurements were obtained from 182 females and 118 males from Igbo ethnic group and 95 females and 105 males of the Yoruba ethnic group between ages 18-68 years. Digital vernier calliper was used to measure the different parameters in each individual with $95 \%$ confidence interval of the statistic.

Results: The result showed generally, that the auricular length and earlobe lengths increased with an increase in age while the auricular width increased irrespective of the advancement in age. Darwinian tubercle in Igbos was 68(22.67\%), Prevalence of pendulous earlobe was $157(52.33 \%)$ and non-pendulous earlobe 143(47.67\%) while in Yorubas Darwinian tubercle was $48(24.0 \%)$. Prevalence of pendulous earlobe $132(66.0 \%)$ and non-pendulous earlobe was $68(34.0 \%)$. The auricles are asymmetrical and continue to grow throughout life in both sexes.

Conclusion: Care should be taken in noting the ages and sex of the individuals before surgical practices is been carried out for each auricle.

Keywords: darwinian tubercle, pendulous, non-pendulous, auricle, igbo, yoruba
Volume 4 Issue I - 2019

\author{
Ezon Ebidor Innocent Edibamode, John \\ Nwolim Paul, Josiah S Hart, Amarachi Ukwen \\ Okere \\ Department of Anatomy, Faculty of Basic Medical Sciences, \\ College of Health Sciences, University of Port Harcourt, Nigeria
}

Correspondence: John Nwolim Paul, Department of Anatomy, Faculty of Basic Medical Sciences, College of Health Sciences, University of Port Harcourt, Choba, Port Harcourt, Rivers State, Nigeria,Email nwolim_paul@uniport.edu.ng

Received: January 24, 2019 | Published: February 26, 2019

\section{Introduction}

Our knowledge of physical anthropology tells us some differing characters between Negroes of which Nigerians are inclusive and some other races; ranging from the Caucasians, Mongloids, Australoids. Anthropometry in physical anthropology refers to the concise measurement of the human individual for the purposes of understanding human physical variations. ${ }^{1}$ It can also be defined as the scientific study of the human body. ${ }^{2}$

Significance of the study: A good knowledge of the differences in the auricles of males and females with increase in age will enable us have a better understanding of the variations as they exist in Nigerian indigenous populations. There exist research works by on auricular dimensions in several other populations. ${ }^{1-13}$

Statement of the problem: There is dearth of information on the prevalence of the Darwinian tubercle in the Nigerian indigenous populations. Hence this study was carried out to investigate and have an indigenous database for these peculiarities in auricles.

\section{Aims of the study}

This study was done to determine the differences in mean auricular lengths, auricular widths and earlobe lengths of males and females with increase in age, prevalence of pendulous and non-pendulous earlobes and Darwinian tubercle in the population.

\section{Brief anatomy of the auricle}

Human earlobe may be free or detached (hanging free from the head). Whether the earlobe is free or attached is a classic example of simple genetic dominance relationship. Freely hanging earlobes are the dominant allele while the attached are recessive (Figure 1). ${ }^{14,15}$ The earlobe is composed of tough areolar and adipose tissue, and connective tissue. The earlobe has a large blood supply and may help to warm the ears. ${ }^{15}$

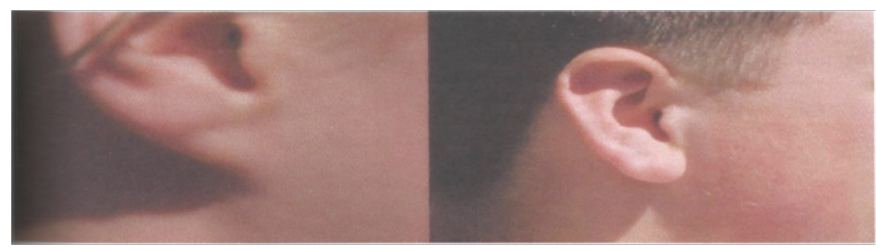

$\mathrm{I}(\mathrm{A})$

I(B)

Figure I (A) Non pendulous. (B) Pendulous earlobes.

The non-cartilagenous lobule is easily pierced for taking blood samples and inserting earrings. The earlobes are normally smooth, but occasionally exhibit creases. Creased earlobes are associated with an increased risk of heart attack and coronary heart diseases. However since earlobes become more creased with age, thus older people are more likely to experience heart disease than younger people. Age may account for the findings linking heart attack to earlobe disease. ${ }^{16}$ The auricle has two surfaces: A lateral or anterior surface and medial or posterior surface (cranial surface). The auricle projects from the side of the skull at varying degrees; so the cranial surface of the auricle might be hidden in some individuals. ${ }^{17}$ The lateral surface of the auricle which is the exposed surface has several prominences and depressions giving it a unique shape. 
The curved rim of the auricle is known as the helix. At the posterior superior aspect of the helix is a small tubercle known as the auricular tubercle (Darwin's tubercle). Darwinian tubercle is a congenital ear condition which often presents as a thickening in the helix at the junction of the upper and middle third. ${ }^{18}$

Darwinian tubercle is very evident about the sixth month of fetal life when the whole auricle has a close resemblance to that of the adult monkeys (Figure 2). ${ }^{18,19}$ The Darwinian tubercle was first noted by Charles Darwin as an evidence of vestigial feature indicating common ancestry among primates. However, Darwin himself named it 'woolnerian tip' after Thomas Woolner, a British sculptor who depicted it in one of his sculptures and has first theorized that it was an atavistic feature. ${ }^{19,20}$
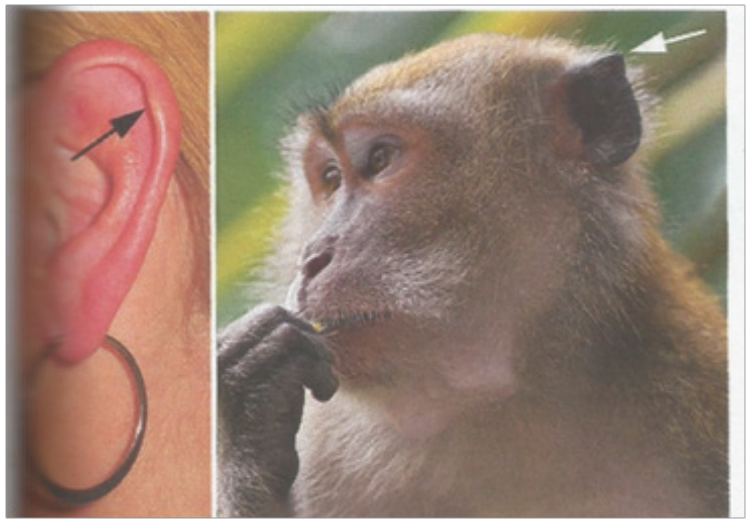

Figure 2 Darwinian tubercle.

\section{Materials and methods}

Research design: The study was cross-sectional.

Sample size and sampling technique: A total of 500 subjects which comprised 300 Igbos' (182 females, 118 males) and 200 Yorubas' (95 females, 105 males) between the ages 18 and 68 years randomly selected.

Criteria for Subject Selection: All subjects used for this study were pure indigenes of the tribes (Igbo and Yoruba) both in Southern Nigeria with no history of auricular trauma or congenital deformities.
Ethical clearance: Ethical clearance was obtained from the Research Ethics Committee of the University of Port Harcourt, Nigeria.

Data collection: The informed consent was obtained from the volunteer subjects before commencement of the study from March 10 - November 11, 2017. The subjects were grouped into five age range: $18-28$ yrs, 29-38yrs, 39-48yrs, 49-58yrs, and 59-68yrs. Each subject was asked to take a sitting position on a chair, the auricular length, width and earlobe lengths were measured using digital vernier caliper as depicted by Bozkir et al. ${ }^{1}$ The auricular length was measured by placing the digital vernier caliper vertically on the auricle and the distance between the highest point of the auricle and the lowest point of the earlobe was read from the caliper. Auricular width was measured by placing the caliper horizontally, and the distance from the tragus to the helix was read from the caliper. The earlobe was measured by placing the caliper vertically and the distance from the intertragic notch of the caudal part of the earlobe was read. The earlobe was examined for the presence of Darwinian Tubercle and the mode of earlobe attachment.

\section{Results and discussions}

The results of the study when the subjects were grouped according to age range revealed that the ear continued to grow throughout life, as had earlier been observed by Purkait and Singh ${ }^{20}$ among Indians; Ruiz $^{12}$ among Spanish individuals. The present study revealed that the auricular length in individuals in Yoruba and Igbo ethnic groups increased steadily with an increase in age. However, between ages 59-68 years, there was a marked increase in auricular lengths in the Yoruba males. This abrupt increase in auricular growth was also observed in the auricular length of the right auricle in Yoruba males. This sharp growth rate could be attributed to the variation in type of food between both ethnic groups. The Yorubas are known for eating a specific three leave yam an indigenous food most common in the Yoruba land that have been implicated in the high rate of growth and multiple births. The earlobe length also increased with increasing age range, as had earlier been observed by Sharma et al. ${ }^{2}$ among Indians. The observations in the present study are consistent with the reports of Sharma et al. ${ }^{2}$ who also reported that there was a marked increase in earlobe length between ages 41-80 years. The results of the present study showed that there was a marked increase in earlobe lengths between 59-68years of age (Table 1-3).

Table I Mean values of the right and left auricular length, width and earlobe of lgbos of each age range

\begin{tabular}{lllllll}
\hline Age range & \multicolumn{2}{l}{ Mean auricular length $(\mathbf{c m})$} & \multicolumn{2}{l}{ Mean auricular width $(\mathbf{c m})$} & \multicolumn{2}{l}{ Mean earlobe length $(\mathbf{c m})$} \\
\hline Igbo males & Right & Left & Right & Right & Left & Right \\
\hline $18-28$ & 6.07 & 5.91 & 3.27 & 3.31 & 1.63 & 1.57 \\
$29-38$ & 6.08 & 5.91 & 3.16 & 3.17 & 1.76 & 1.61 \\
$39-48$ & 6.08 & 6.06 & 3.2 & 3.28 & 1.82 & 1.72 \\
$49-58$ & 6.56 & 6.35 & 3.21 & 3.28 & 1.84 & 1.77 \\
$59-68$ & 6.83 & 6.73 & 3.44 & 3.6 & 2.33 & 2.13 \\
Igbo females & & & & & & \\
18-28 & 5.89 & 5.75 & 2.96 & 3.08 & 1.59 & 1.55 \\
$29-38$ & 6 & 5.87 & 3.02 & 3.06 & 1.72 & 1.59 \\
$39-48$ & 6.11 & 5.87 & 3.17 & 3.22 & 1.79 & 1.66 \\
$49-58$ & 6.29 & 6.18 & 2.95 & 3.11 & 1.79 & 1.68 \\
$59-68$ & 6.32 & 6.2 & 2.94 & 3.08 & 1.83 & 1.73 \\
\hline
\end{tabular}


Table 2 Mean values of the right and left auricular length, width and earlobe of Yorubas of each age range

\begin{tabular}{lllllll}
\hline Age range & \multicolumn{2}{l}{ Mean auricular length $(\mathbf{c m})$} & \multicolumn{2}{l}{ Mean auricular width $(\mathbf{c m})$} & \multicolumn{2}{l}{ Mean earlobe length $(\mathbf{c m})$} \\
\hline Yoruba males & Right & Left & Right & Left & Right & Left \\
\hline $18-28$ & 6.1 & 5.89 & 3.03 & 3.25 & 1.67 & 1.59 \\
$29-38$ & 6.33 & 6.15 & 2.99 & 3.17 & 1.79 & 1.69 \\
$39-48$ & 6.34 & 6.07 & 3.02 & 3.23 & 1.91 & 1.83 \\
$49-58$ & 6.9 & 6.65 & 3.23 & 3.32 & 2.37 & 2.03 \\
$59-68$ & 7.8 & 7.76 & 3.28 & 3.45 & 2.8 & 2.17 \\
Yoruba females & & & & & & 1.63 \\
$18-28$ & 5.9 & 5.74 & 2.71 & 3.07 & 1.57 \\
$29-38$ & 6.01 & 5.89 & 2.75 & 3.09 & 1.72 & 1.6 \\
$39-48$ & 6.12 & 5.98 & 2.78 & 3.15 & 1.8 & 1.67 \\
$49-58$ & 6.33 & 6.19 & 2.76 & 3.12 & 1.84 & 1.72 \\
$59-68$ & 6.88 & 6.46 & 2.75 & 3.1 & 1.86 & 1.74 \\
\hline
\end{tabular}

Table 3 Prevalence of Darwinian tubercle, pendulous and Non-pendulous earlobes

\begin{tabular}{lllll}
\hline & \multicolumn{2}{l}{ Darwinian tubercle } & Earlobe attachment \\
\hline Ethnic Group & Present & Absent & Pendulous Earlobe & Non- Pendulous Earlobe \\
lgbo & $68(22.67 \%)$ & $232(77.33 \%)$ & $157(52.33 \%)$ & $143(47.67 \%)$ \\
Yoruba & $48(24.0 \%)$ & $152(76.0 \%)$ & $132(66.0 \%)$ & $68(34.0 \%)$ \\
\hline
\end{tabular}

The auricular width growth was independent of increase in age as had earlier been reported by Pelz and Stein ${ }^{11}$ among Italians. According to the present study, auricular width of the female in both ethnic groups increased in a similar pattern, and the auricular width of males in both ethnic groups increased in the similar pattern. The non-pendulous earlobes were less prevalent in both samples; this finding was in accordance to the research carried out by Williams and Hughes $^{13}$ in Lagos (Nigeria). The prevalence of Darwinian tubercle in the present study showed $22.67 \%$ and $24 \%$ in the Igbo and Yoruba ethnic groups respectively. This result negates the results of Ruiz ${ }^{12}$ among Spanish individuals.

\section{Conclusion}

The results of this study has shown that the auricular length, width and earlobe length grew with advancement in age, the prevalence of Darwinian tubercle, Pendulous and Non-pendulous earlobe attached in both ethnic groups which could serve as a database and reference for the Nigerian indigenous populations. This would be useful to clinicians and physical anthropologists.

\section{Recommendation}

We strongly recommend that more investigations be carried out in other Nigerian populations to generate more data that will serve as a national data for the nation.

\section{Acknowledgments}

We sincerely appreciate the entire members of the Department of Anatomy, University of Port Harcourt, Nigeria for their support during the research.

\section{Conflicts of interest}

We write to state that there is no conflict of interest.

\section{Source of funding}

Self-funding.

\section{Author's contribution}

We write to state that all authors have contributed significantly, and that all authors are in agreement with the contents of the manuscript. 'Author A' (Ezon-Ebidor Innocent Edibamode) designed the study and protocol, 'Author B' (John Nwolim Paul) reviewed the design, protocol and examined the intellectual content, Author C' (Josiah S. Hart) wrote the first draft of the manuscript and managed the literature search, 'Author D' (Amarachi Ukwen Okere) managed the analyses of the study. All authors read and approved the final manuscript.

\section{References}

1. Bozkır Gülhal M, Metin Yavuz, Pınar Karakaş, et al. Morphometry of the External Ear in Our Adult Population. Aesthetic Plast Surg. 2006;30(1):81-85.

2. Sharma Anshu, AdhuNavjot K, Sharma Kumar, et al. Morphometric study of the ear lobule in North West Indian male subjects. Anat Sci Int. 2007;82(2):98-104.

3. Raeaf Kollali EI. Earlobe morphology: a simple classification of normal earlobes. J Plast Reconstr Aesthet Surg. 2009;62(2):277-280.

4. Asai. Anthropometric study of the ear in Japan. British Medical Journal. 1996;312(7030):582.

5. Azaria R, Adler N, Silfen R, et al. Morphometry of the adult earlobe. Plast Reconstr Surg. 2003;7(111):2398-2404.

6. Brucker Michael J, Patel Jagneti, Sullivian Patrick K, et al. A morphometric study of the external ear- Age related differences. Plast Reconstr Surg. 2003;2(112):647-654.

7. Farkas LG, Posnick JC, Hreczko TM. Anthropometric growth study of the Ear. Cleft Palate Craniofac J. 2002;29(4):324-329. 
8. Barut Cataguy, Aktunc Erol. Anthropometric study of the ear in a Group of Turkish Primary school students. Aesthetic Plast Surg. 2006;30(2):255-259.

9. Chae SW, Cho JG, Kion DH, et al. Anthropometric study of the auricle in Korean. Korean Medical Journal Information. 2002;45(7):662-665.

10. Eijernan Lynn, Van Der LugtCor, et al. Cross sectional anthropometric study of the external ear. J Forensic Sci. 2007;52(2):286-293.

11. Pelz L, Stein B. Clinical assessment of the ear size in children and adolescent. Padiatr Grenzgeb. 1990;29(3):229-235.

12. Ruiz A. An anthropometric study of the adult ear in an adult population. International Journal of Anthropology. 1986;1(2):135-143.

13. Williams GO, Hughes AE. Frequencies of attached and free earlobes in Lagos (Nigeria). Am J Phys Anthropol. 2005;72(3):399-401.

14. Kadam YR, Shah YM, Kore P. Diagonal earlobe crease: Prevalence and association with medical ailments. Journal of Clinical and Preventive Cardiology. 2018;7(2):49-53.
15. Keith Moore L, Arthur Dalley F, Anne Agur MR. External ear. Clinically Oriented Anatomy, 6th ed. WolterKluwers/ Lippincott Williams and Wilkins; 2008. 966 p.

16. Rodríguez-López C, Garlito-Díaz H, Madroñero-Mariscal R. Earlobe Crease Shapes and Cardiovascular Events. Am J Cardiol. 2015;116(2):286-293.

17. Korkmaz L, Ağaç MT, Acar Z. Earlobe crease may provide predictive information on asymptomatic peripheral arterial disease in patients clinically free of atherosclerotic vascular Disease. Angiology. 2014;65(4):303-307.

18. Iorgoveanu C, Zaghloul A, Desai A, et al. Bilateral Earlobe Crease as a Marker of Premature Coronary Artery Disease. Cureus. 2018;10(5):e2616.

19. Tiffany Y Loh, Philip R Cohen. Darwin's Tubercle: Review of a Unique Congenital Anomaly. Dermatol Ther (Heidelb). 2016;6(2):143-149.

20. Purkait Ruma, Singh Priyanka. Anthropometry of the normal human auricle. Aesthetic Plast Surg. 2007;31(4):372-379. 